\title{
Dipeptidyl peptidase 4 inhibitors and bullous pemphigoid - more evidence of a link: a report of three cases
}

\author{
AMRITA RANDHAWA, DONNA TORLEY, ALASTAIR KERR, GRANT WYLIE
}

\begin{abstract}
Recently, dipeptidyl peptidase 4 (DPP-4) inhibitors, an antidiabetic medication, have been implicated in the development of bullous pemphigoid, the most common autoimmune cutaneous blistering disorder. In this report we present three cases of DPP-4 associated bullous pemphigoid in our dermatology department. These cases illustrate the importance for clinicians to consider a drug as a trigger for bullous pemphigoid in elderly patients with diabetes.
\end{abstract}

Key words: oral anti-hyperglycaemic agent, bullous pemphigoid, DPP-4 inhibitors

\section{Introduction}

Bullous pemphigoid (BP) is the most common autoimmune blistering skin disorder which mainly affects the elderly. Circulating autoantibodies target hemidesmosomal proteins (BP180 and BP 230) of basal keratinocytes leading to damage of the dermoepidermal junction. ${ }^{1}$ Its clinical presentation can vary from pruritus, excoriations, urticated erythematous plaques to widespread tense bullae. More recently, multiple epidemiological studies worldwide have suggested that dipeptidyl peptidase 4 (DPP-4) inhibitors, commonly known as gliptins, a relatively new oral anti-hyperglycaemic agent, may be implicated in triggering the development of BP. 2,3 We report three cases of BP felt to be associated with the use of a DPP-4 inhibitor.

\section{Case reports}

\section{Patient 1}

A 78-year-old man presented with a 6-month history of a blistering rash. He was known to have type 2 diabetes mellitus (T2DM) which had become harder to control with first-line agents. Linagliptin was added to his treatment 12 months previously. Examination revealed tense bullae on his hands, feet and limbs of

Department of Dermatology, Queen Elizabeth University Hospital, Glasgow, UK

Address for correspondence: Dr Amrita Randhawa Department of Dermatology, Queen Elizabeth University Hospital, 1345 Govan Road, Glasgow G51 4TF, UK

E-mail: arandhawa@nhs.net

Br J Diabetes 2020;20:147-148

https://doi.org/10.15277/bjd.2020.262
Figure 1. Erythematous urticated eruption with multiple intact tense fluid-filled blisters on limbs and trunk

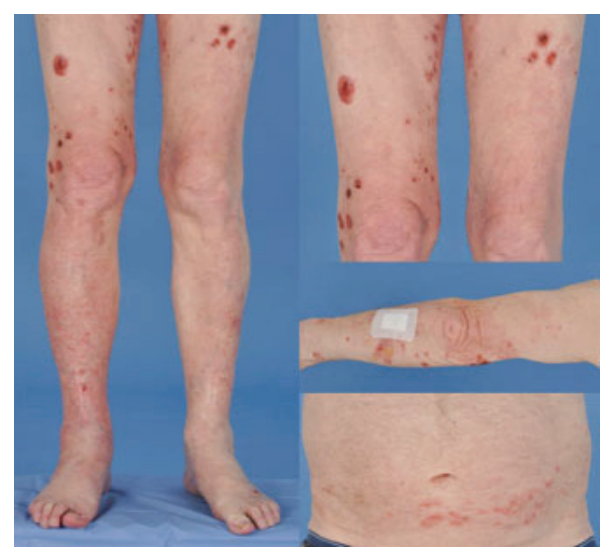

various sizes and stages of evolution. The history was complicated by a pre-existing history of porphyria cutanea tarda. Prior to the possible connection with linagliptin, oral prednisolone, tetracycline and nicotinamide were used to treat the skin. His diabetic control deteriorated and subcutaneous insulin was required.

\section{Patient 2}

An 82-year-old man with a background of cognitive impairment presented from a nursing home to on-call dermatology with widespread pruritic tense bullae. He had a history of generalised pruritus for the last 1 year. He was admitted for intensive topical treatment including clobetasol propionate. A history of T2DM and 24 months of treatment with linagliptin was noted.

\section{Patient 3}

A 79-year-old man developed BP after being on vildagliptin for 16 months (Figure 1). He was switched to vildagliptin because he had developed a pruritic rash with sitagliptin. He was treated with systemic corticosteroids and commenced on empagliflozin, a sodium-glucose linked transporter 2 inhibitor.

All three patients had diagnostic skin biopsies and direct immunofluorescence to confirm the diagnosis (Table 1). DPP-4 inhibitors were stopped in all patients and, after 4-8 weeks of cessation, the clinical appearances of BP quickly resolved despite rapid reduction in topical and oral corticosteroid therapy. 
Table 1 Breakdown of the histology and immunological analysis of the three patients

\begin{tabular}{|c|c|c|c|}
\hline Patient & Histology & $\begin{array}{l}\text { Direct } \\
\text { immunofluorescence }\end{array}$ & $\begin{array}{l}\text { Circulating } \\
\text { pemphigoid } \\
\text { skin } \\
\text { autoantibody }\end{array}$ \\
\hline 1 & $\begin{array}{l}\text { Dense infiltrate of } \\
\text { eosinophils within } \\
\text { the superficial } \\
\text { dermis }\end{array}$ & $\begin{array}{l}\text { Linear positivity for } \\
\text { IgG and C } 3 \text { at the } \\
\text { basement membrane }\end{array}$ & Negative \\
\hline 2 & $\begin{array}{l}\text { Subepidermal } \\
\text { bulla with } \\
\text { abundant } \\
\text { eosinophils }\end{array}$ & $\begin{array}{l}\text { Linear positivity for } \\
\text { lgG and C } 3 \text { at the } \\
\text { basement membrane }\end{array}$ & Positive \\
\hline 3 & $\begin{array}{l}\text { Subepidermal } \\
\text { blister with } \\
\text { inflammatory cells. } \\
\text { Chronic } \\
\text { inflammatory cell } \\
\text { infiltrate in the } \\
\text { dermis which } \\
\text { includes } \\
\text { lymphocytes and } \\
\text { eosinophils }\end{array}$ & $\begin{array}{l}\text { Linear positivity for } \\
\text { IgG and C } 3 \text {. Weak } \\
\text { granular positivity } \\
\text { with IgM }\end{array}$ & Negative \\
\hline
\end{tabular}

\section{Discussion}

DPP-4 inhibitors are second-line antidiabetic agents (currently five gliptins are available in the UK). These work by promoting insulin secretion by blocking degradation of incretin hormones improving glycaemic control. ${ }^{2}$ The mechanisms by which DPP-4 inhibitors trigger BP remain unclear. DPP-4, a glycoprotein, is expressed on cell membrane surfaces including keratinocytes and immune cells. Inhibition of DPP-4 may therefore affect epidermal basement membranes, promote immune system activation and stimulate pro-inflammatory pathways. ${ }^{2}$

The latency period between the onset of BP and introduction of the DPP-4 inhibitor was relatively long in our patients, and this was also mirrored in previous pharmacovigilance studies ranging from 5 to 25 months. . $^{3,4}$ This can subsequently lead to a delay in diagnosis and delay in withdrawing the offending trigger. It also raises the question of whether this is a drug-induced or drug-exacerbated phenomenon in those who are susceptible. All three patients were men with a mean age of 80 years, supporting data in previous reports highlighting that this group is high risk.

Three types of gliptins (sitagliptin, linagliptin and vildagliptin) were implicated in triggering BP in our cohort of patients, suggesting a class effect of gliptins. Having said that, vildagliptin is the most common gliptin to trigger BP according to the literature. ${ }^{4}$ Furthermore, a recent Japanese study suggests that gliptinassociated BP is less inflammatory than conventional BP both clinically and histologically, however we did not observe this in our cohort of patients. ${ }^{5}$ It has also been observed that patients

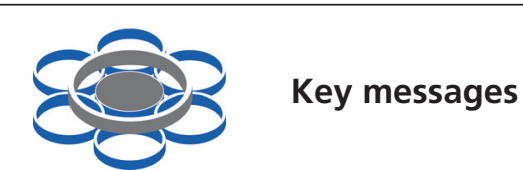

- An increasing body of evidence suggests DPP-4 inhibitors are associated with the development of bullous pemphigoid

- The latency period can range from 5 months to 2 years

- It is important to consider drug-induced bullous pemphigoid in older patients taking a DPP-4 inhibitor

with DPP-4 induced BP tend to have a lower positivity rate of autoantibody titres, as seen in this case series. ${ }^{6}$ This is likely due to the autoantibodies specifically targeting the mid-portion of BP180 antigen but not NC16A domain as seen in classic BP. A skin biopsy and direct immunofluorescence on perilesional skin therefore remains the gold standard for diagnosis even in DPP4 induced BP.

In summary, BP, an autoimmune blistering disorder in the elderly, can be triggered by DPP-4 inhibitors and withdrawal of this drug can result in sustained remission. With increasing population age and multiple comorbidities, polypharmacy is more prevalent. More patients will undoubtedly be prescribed a DPP4 inhibitor. It is therefore crucial for physicians to be made aware of this association to allow prompt diagnosis and management.

\section{Conflict of interest None. \\ Funding None. \\ Patient's consent Obtained from patient 3 to use photographs.}

\section{References}

1. Schmidt E, Zillikens D. Pemphigoid diseases. Lancet 2013;381(9863): 320-32. https://doi.org/10.1016/S0140-6736(12)61140-4

2. Hung CT, Liu JS, Cheng CY, et al. Increased risk of bullous pemphigoid in dipeptidyl peptidase 4 inhibitors: a nationwide, population-based, cohort study in Taiwan. J Dermato/ 2020;47(3):245-50. https://doi.org/ 10.1111/1346-8138.15195

3. Bene J, Moulis G, Bennani I, et al, French Association of Regional PharmacoVigilance Centres. Bullous pemphigoid and dipeptidyl peptidase IV inhibitors: a case-noncase study in the French Pharmacovigilance Database. Br J Dermatol 2016;175(2):296-301. https://doi.org/ 10.1111/bjd.14601

4. García M, Aranburu MA, Palacios-Zabalza I, Lertxundi U, Aguirre C. Dipeptidyl peptidase-IV inhibitors induced bullous pemphigoid: a case report and analysis of cases reported in the European Pharmacovigilance Database. J Clin Pharm Ther 2016;41(3):368-70. https://doi.org/ 10.1111/jcpt.12397

5. Izumi K, Nishie W, Mai $Y$, et al. Autoantibody profile differentiates between inflammatory and noninflammatory bullous pemphigoid. J Invest Dermatol 2016;136(11):2201-10. https://doi.org/10.1016/ j.jid.2016.06.622

6. Nishie W. Dipeptidyl peptidase IV inhibitor-associated bullous pemphigoid: a recently recognized autoimmune blistering disease with unique clinical, immunological and genetic characteristics. Immunol Med 2019;42(1):22-8. https://doi.org/10.1080/25785826.2019.1619233 